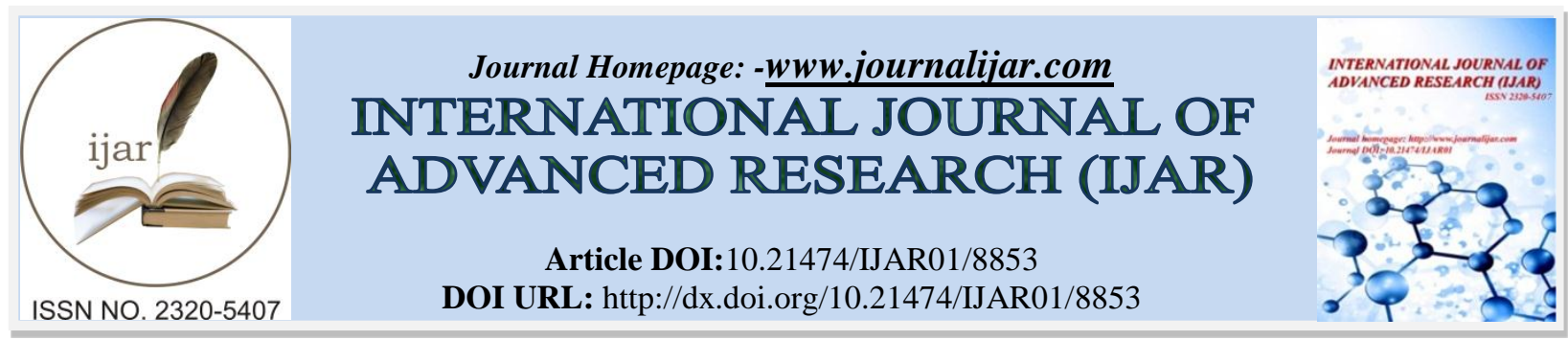

RESEARCH ARTICLE

\title{
CLINICAL PROFILE OF INTRA-CEREBRAL HAEMORRHAGIC STROKE PATIENTS IN AN ETHNIC POPULATION OF NORTH INDIA.
}

\author{
Dr. Atif Rasool Kawoosa ${ }^{1}$, Dr. Sajad Ahmed Tak ${ }^{2}$ and Dr. Hena Naqash ${ }^{2}$
}

1. Post DM Senior, Resident Department of Neurology GSSH, Srinagar.

2. Post MD Senior, Resident Department of Nuorology GSSH, Srinagar.

\section{Manuscript Info}

Manuscript History

Received: 08 February 2019

Final Accepted: 10 March 2019

Published: April 2019

Key words:-

Intra-Cerebral Haemorrhage. Clinical

Profile. Kashmir. Hypertension.

\section{Abstract}

Introduction:Given the high prevalence of Intra Cerebral Haemorrhage (ICH) in the Kashmir Valley, an associated very high morbidity and mortality and the scarcity of studies from our part of the world, it becomes relevant and prudent to study the clinical parameters of ICH in our Valley which in turn would potentially be translated into preventive measures.

Aim: We aimed to study various clinico-biochemical parameters of the ICH patients in our region.

\section{Methodology:}

We studied 150 consecutive ICH patients admitted to our hospital, including their age, gender, blood pressures, NCCTs and ICH scores, using a pretested, semi-structured questionnaire to collect the information. Statistical analysis was performed by using SPSS software (V.11.5).

Results:The majority of ICH patients belonged to a higher age group ( $46 \%$ above age $>60$ years and $38.6 \%$ in age range $40-60$ years). There was no significant difference between the occurrence of ICH in males vs females ( $\mathrm{p}$ value $<0.05$ ). Hypertension was a major association of ICH with more than two-thirds of patients being hypertensive (75.33\%). Non- Lobar ICH (72\%) was much more common than the Lobar ICH (28\%), with former being more significantly associated with underlying Hypertension and later with advancing age.

Conclusion:ICH, a major health burden in our community is highly associated with Hypertension. Since Hypertension in itself has an unusually high prevalence in the Valley, so a relevant intervention would provide potential primary preventive measure to decrease the burden of ICH in our community.

Copy Right, IJAR, 2019,. All rights reserved.

\section{Introduction:-}

Stroke is defined as a focal (or at times global) neurological impairment of sudden onset, lasting more than $24 \mathrm{~h}$ (or leading to death) and of presumed vascular origin . According to WHO, 15 million people worldwide suffer a stroke annually and of these 5 million die while another 5 million are left disabled. ${ }^{1}$ Stroke remains the most 
common cause of disability in developed countries. ${ }^{2,3}$ It is estimated that by 2020,19 out of 25 million annual stroke deaths will be in developing countries. ${ }^{4}$

Intra-Cerebral Haemorrhage (ICH) victims have a grim outcome with ensuing death or severe disability for more than 50\%. ${ }^{5}$ Of the thousands of stroke survivors each year, approximately $30 \%$ require assistance with activities of daily living, $20 \%$ require assistance with ambulation, and $16 \%$ require institutional care. ${ }^{6}$

About $85 \%$ of strokes are due to cerebral ischemia and $15 \%$ are due to primary intracerebral hemorrhage ${ }^{7,8}$, especially in the western literature. However, overall, ICH accounts for $10-35 \%$ of stroke cases depending on the population studied ${ }^{9}$ Like some series from Asian countries such as that from Shibata, Japan, with reported severalfold higher incidence rates of $\mathrm{ICH}^{10}$, ICH in our valley was reported to be the commonest stroke-type observed in Kashmir accounting for close to two third of strokes with male preponderance. ${ }^{11}$ Consequently it becomes more relevant to study ICH in Kashmir, especially the study of clinical parameters that in turn has potential to be translated into preventive strategies.

\section{Aim and methodology:-}

We aimed to study various clinical parameters of ICH patients presenting to the tertiary care hospital in Neurology department. $150 \mathrm{ICH}$ patients were considered. A pretested, semi-structured questionnaire was used to collect the information on clinical parameters with prior consent of the patients. The data collected included Gender, Age and Hypertension. Also based on non-contrast CT scan patients were recognized as Lobar vs Non-Lobar ICH and ICH Scoring for severity of $\mathrm{ICH}^{12}$ was assessed. Statistical analysis was performed by using SPSS software (V.11.5). Statistical significance was considered with $\mathrm{p}$-value $\leq 0.05$. The data was collected from a relevant study approved by the ethical committee of the institute (No. SIMS 1 131/IEC-SKIMS/2017-239).

\section{Results:-}

The incidence of ICH was higher with increasing age and was less common below 40 years of age (14.6\% below 40 years of age). Majority of patients $(\mathbf{4 6 \%}$ of all) belonged to age $>60$ years. $38.6 \%$ of patients belonged to age group $41-60$ years.

There was no significant difference between the occurrence of ICH in males vs females (p value $<\mathbf{0 . 0 5}$ ), although males patients were slightly more below 60 years of age and female patients were more $>60$ years of age.

More than two thirds of all ICH patients were hypertensive (75.33\%). Underlying hypertension was more frequently seen with ICH patients in the middle age group, $40-60$ years $(\mathbf{8 4 . 4 \%})$, and was seen comparatively less frequently in patients aged 40 or less $(\mathbf{6 3 . 6 \%})$. In the age group $>60$ years, $77 \%$ of patients had underlying hypertension. There was no significant difference between the incidence of hypertension between Males and Females in each age group ( $\mathbf{p}$ value $<\mathbf{0 . 0 5})$.

Only about $\mathbf{2 8 \%}$ of all ICH cases were Lobar haemorrhages, while the rest were Nonlobar (72\%). There was no significant gender difference in the distribution of Lobar and Nonlobar ICH (p value <0.05). Lobar ICH was proportionately much less common in the age group of $40-60$ years. Nonlobar ICH had a significant association with underlying hypertension ( $\mathbf{p}$ value $>\mathbf{0 . 0 5})$.

The significant majority of ICH patients were having an ICH Score of 2 or 3 at presentation, in all age groups and among both genders (p value $\mathbf{> 0 . 0 5}$ ). Severity of ICH was seen proportionately more in the age group of $>60$ years.

\begin{tabular}{|c|c|c|c|c|c|c|c|}
\hline Age & \multicolumn{2}{|l|}{ Gender } & Hypertensive & \multicolumn{2}{|c|}{ Location Of ICH } & \multicolumn{2}{|c|}{ ICH Score } \\
\hline \multirow{7}{*}{$<40$} & \multirow{5}{*}{ Males } & \multirow[t]{5}{*}{12} & \multirow[t]{5}{*}{7} & \multirow{3}{*}{ Lobar } & \multirow[t]{3}{*}{3} & 0 & 1 \\
\hline & & & & & & 1 & 4 \\
\hline & & & & & & 2 & 4 \\
\hline & & & & \multirow[t]{2}{*}{ Nonlobar } & \multirow[t]{2}{*}{9} & 3 & 2 \\
\hline & & & & & & 4 & 1 \\
\hline & \multirow[t]{2}{*}{ Females } & \multirow[t]{2}{*}{10} & \multirow[t]{2}{*}{7} & \multirow[t]{2}{*}{ Lobar } & \multirow[t]{2}{*}{3} & 0 & 1 \\
\hline & & & & & & 1 & 2 \\
\hline
\end{tabular}




\begin{tabular}{|c|c|c|c|c|c|c|c|}
\hline & & & & & & 2 & 3 \\
\hline & & & & Nonlobar & 7 & 3 & 2 \\
\hline & & & & & & 4 & 2 \\
\hline & Males & 32 & 27 & Lobar & 6 & 0 & 3 \\
\hline $41-60$ & & & & & & 1 & 6 \\
\hline & & & & & & 2 & 13 \\
\hline & & & & Nonlobar & 26 & 3 & 9 \\
\hline & & & & & & 4 & 1 \\
\hline & Females & 26 & 22 & Lobar & 6 & 0 & 4 \\
\hline & & & & & & 1 & 5 \\
\hline & & & & & & 2 & 9 \\
\hline & & & & Nonlobar & 20 & 3 & 7 \\
\hline & & & & & & 4 & 1 \\
\hline & Males & 32 & 24 & Lobar & 12 & 0 & 1 \\
\hline$>60$ & & & & & & 1 & 4 \\
\hline & & & & & & 2 & 13 \\
\hline & & & & Nonlobar & 20 & 3 & 10 \\
\hline & & & & & & 4 & 4 \\
\hline & Females & 38 & 30 & Lobar & 12 & 0 & 3 \\
\hline & & & & & & 1 & 7 \\
\hline & & & & & & 2 & 13 \\
\hline & & & & Nonlobar & 26 & 3 & 11 \\
\hline & & & & & & 4 & 4 \\
\hline
\end{tabular}

Table 1:-Distribution/frequency of ICH Patients in various Clinical Parameters.

\section{Discussion:-}

Consistent with the fact that the incidence of ICH increases with advancing age ${ }^{13,14}$ which is a feature that applies to all types of stroke, both ischemic and hemorrhagic, the incidence of ICH was higher with increasing age in our study. CAA related ICH also plays its role in this age dependent increase in incidence ${ }^{15}$.

Although gender in general is not considered a specific risk factor for $\mathrm{ICH}$, however studies have shown gender disparities - men having higher incidence of ICH compared to women. ${ }^{16,17}$ Our study also showed a non-significant but higher incidence of ICH in men in Age $<60$ patients. In age $>60$ years, women were more in number, though non-significantly but consistent with the overall predilection of men getting ICH at younger age than women. ${ }^{16,17}$

The role of hypertension as a leading risk factor is well established, and its frequency has been estimated to be between $72 \%$ and $81 \% .^{18,19}$ In the INTERSTROKE study, hypertension (self-reported history or mean blood pressure $>160 / 90$ ) was the strongest risk factor for $\mathrm{ICH}$, accounting for $73.6 \%$ of the population-attributable risk. ${ }^{20}$ Likewise, our study cases also showed a high prevalence of hypertension, i.e., $75 \%$, a percentage consistent with that of previous studies, $72 \%$ and $81 \% \cdot{ }^{18,19}$ Moreover, Kashmir population, in particular, is known to have a high prevalence of hypertension. In a community based survey in rural Kashmir, 58\% were detected to have hypertension. ${ }^{21}$

Lobar ICH was seen less frequently than Non-Lobar (Gangiono-Thalamic) ICH and was seen predominantly in the higher age group. Around $20 \%$ of all ICH patients below 40 years of age were Lobar ICH, while as around $35 \%$ of all ICH patients above 40 years of age were Lobar ICH. Stroke Registry (Dijon, France) found that, although incidence of ICH appeared stable between 1985 and 2008, the incidence had decreased 50\% in individuals below 60. Conversely, it had increased roughly $80 \%$ in people aged $\geq 75$ years. This increased incidence was driven largely by lobar ICH which in-turn in its substantial part can be attributed to CAA related increase in ICH with age ${ }^{15,22}$, and also coincides with an increase in use of antithrombotic therapy. Along with the non-significant gender difference seen, the age related high frequency of Lobar ICH is consistent with advancing age being the strongest clinical risk factor for CAA-related ICH, as predicted by the age dependence of the underlying disease ${ }^{23,24}$, and is also consistent with the finding that there is no marked predilection for gender in either clinical (54\% men, $46 \%$ women) ${ }^{18}$ or pathologic $(49 \% \text { men, } 51 \% \text { women })^{25}$ series 
Non-Lobar ICH had a significant association with underlying hypertension which was not as strong the case Lobar ICH. The etiologic factors in lobar ICH may be somewhat different from those in other forms of ICH, particularly with regard to a less significant role of hypertension. ${ }^{26,27}$ Ropper and Davis ${ }^{28}$ reported chronic hypertension in only $31 \%$ of their cases of lobar ICH, and in the series reported by Kase et al., ${ }^{29}$ only $50 \%$ of the patients had elevated blood pressure on admission; in half of this group high blood pressure had been documented before the hemorrhage. In Weisberg's ${ }^{30}$ study, only $33 \%$ of the patients with lobar ICH had hypertension compared with $81 \%$ of the patients with deep (ganglionic-thalamic) ICHs.

The severity of ICH, as was assessed by ICH Scoring, showed a trend of higher severity with advancing age. This finding is also consistent with the general trend including the finding of Stein and colleagues project, that by the year 2050 , the proportion of all patients with $\mathrm{ICH} \geq 80$ years will be 2.5 -fold higher than in 2009 , with substantial increases in ICH cases (35.2\% increase), severe disability (36.8\%), and in-hospital mortality $(60.2 \%) .{ }^{31}$

\section{Bibliography:-}

1. World Health Organization. WHO STEPS stroke manual : the WHO STEPwise approach to stroke surveillance / Noncommunicable Diseases and Mental Health, Geneva (CH). WHO. 2005: (Section 1) Introduction p1-4

2. Murray CJ, Lopez AD. Mortality by cause for eight regions of the world: Global burden of disease study. Lancet. 1997;349(9061):1269-76

3. Wolfe CD. The impact of stroke. Br Med Bull 2000;56(2):275-86

4. Lemogoum D, Degaute JP, Bovet P. Stroke Prevention, Treatment, and Rehabilitation in Sub-Saharan Africa. Am J Prev Med. 2005 Dec;2:9(5 Suppl 1):95-101

5. Broderick J, Connolly S, Feldmann E, Hanley D, Kase C, Krieger D et al. Stroke. 2007;38(6):2001-2023

6. Robert B. Daroff, Joseph Jankovic, John C Mazziotta, Scott L Pomeroy. Bradley's Neurology in Clinical Practice.Seventh Edition:Elsievier.2016.p921

7. Adams HP, Bendixen BH, Kappelle LJ, Biller J, Love BB, Gordon DL, et al. Classification of subtype of acute ischemic stroke. Definitions for use in a multicenter clinical trial. TOAST. Trial of Org 10172 in Acute Stroke Treatment.Stroke. 1993;24:35-41.

8. Philip M, Bath W, Lees KR. ABC of arterial and venous disease. BMJ. 2000;320:920-3.

9. J.P. Mohr, Philip A. Wolf, James C. Grotta, Michael A. Moskowitz, Marc Mayberg, Rüdiger von Kummer. Stroke: Pathophysiology, Diagnosis, and Management. 5th edition. NewYork U.S.A.; 28: 466

10. Tanaka H, Ueda Y, Date C, et al. Incidence of stroke in Shibata, Japan, 1976-1978. Stroke 1981;12:460.

11. Clinico-radiological profi le of strokes in Kashmir valley, North-West India: A study from a university hospital Parvaiz A Shah MD DM, G Hussain Bardi MD, Bashir A Naiku MD DM, A Khaliq Dar MD, Rakesh K Kaul MD Neurology Asia 2012; 17(1): 5 - 11

12. Hemphill JC, Bonovich DC, Besmertis L, Manley GT, Johnston SC. The ICH Score. A Simple, Reliable Grading Scale for Intracerebral Hemorrhage.. Stroke. April 2001;32:891-897

13. van Asch CJ, Luitse MJ, Rinkel GJ, et al. Incidence, case fatality, and functional outcome of intracerebral haemorrhage over time, according to age, sex, and ethnic origin: a systematic review and meta-analysis. Lancet Neurol 2010;9:167.

14. Harmsen P, Wilhelmsen L, Jacobsson A. Stroke incidence and mortality rates 1987 to 2006 related to secular trends of cardiovascular risk factors in Gothenburg, Sweden. Stroke 2009;40:2691.

15. Itoh Y, Yamada M, Hayakawa M, et al. Cerebral amyloid angiopathy: A significant cause of cerebellar as well as lobar cerebral hemorrhage in the elderly. J Neurol Sci 1993;116:135.

16. Sex differences in incidence, pathophysiology, and outcome of primary intracerebral hemorrhage. Gokhale $\mathrm{S}$, Caplan LR, James ML Stroke. 2015 Mar; 46(3):886-92

17. The epidemiology of intracerebral hemorrhage in the United States from 1979 to 2008. Rincon F, Mayer SA Neurocrit Care. 2013 Aug; 19(1):95-102

18. Mohr JP, Caplan LR, Melski JW, et al. The Harvard Cooperative Stroke Registry: A prospective registry. Neurology 1978;28:754

19. Furlan AJ, Whisnant JP, Elveback LR. The decreasing incidence of primary intracerebral hemorrhage: A population study. Ann Neurol 1979;5:367.

20. O'Donnell MJ, Xavier D, Liu L, et al. Risk factors for ischaemic and intracerebral haemorrhagic stroke in 22 countries (the INTERSTROKE study): a case-control study. Lancet 2010;376:112.

21. Razdan S, Kaul RL, Motta A, Kaul S. Cerebrovascular disease in rural Kashmir, India. Stroke 1989;20:1691-3

22. Tomonaga M. Cerebral amyloid angiopathy in the elderly. J Am Geriatr Soc 1981;29:151. 
23. Greenberg SM, Vonsattel J-PG. Diagnosis of cerebral amyloid angiopathy: Sensitivity and specificity of cortical biopsy. Stroke 1997;28:1418

24. Vinters HV, Gilbert JJ. Cerebral amyloid angiopathy: Incidence and complications in the aging brain. II: The distribution of amyloid vascular changes. Stroke 1983;14:924.

25. Vinters HV. Cerebral amyloid angiopathy: A critical review. Stroke 1987;18:311

26. Mutlu N, Berry RG, Alpers BJ. Massive cerebral hemorrhage: Clinical and pathological correlations. Arch Neurol 1963;8:74.

27. McCormick WF, Rosenfield DB. Massive brain hemorrhage: A review of 144 cases and an examination of their causes. Stroke 1973;4:946

28. Ropper AH, Davis KR. Lobar cerebral hemorrhages: Acute clinical syndromes in 26 cases. Ann Neurol 1980;8:141

29. Kase CS, Williams JP, Wyatt DA, et al. Lobar intracerebral hematomas: Clinical and CT analysis of 22 cases. Neurology 1982;32:1146

30. Herold S, von Kumer R, Jaeger CH. Follow-up of spontaneous intracerebral haemorrhage by computed tomography. J Neurol 1982;228:267.

31. Stein M, Misselwitz B, Hamann GF, et al. Intracerebral hemorrhage in the very old: future demographic trends of an aging population. Stroke 2012;43:1126. 